\title{
RESPONSE OF PACKAGED TOMATOES (Lycopersicon Esculentum Mill)TO AXIALLY AND RADIALLY COMPRESSIVE LOADING
}

\author{
F. R. Falayi ${ }^{1, *}$ and E. S. Ajayi ${ }^{2}$ \\ 1 Dept. of Agricultural \& Environmental Engr., Federal Univ. of TEChNology, AKURE. Ondo State, NigERIA \\ 2 DEPT. OF AGRiculturAl \& BIORESOURCES ENGINEERING, FEDERAl UNIVERSITY OYE - EKITI, EKITI STATE. NIGERIA \\ E-mail addresses: 1 falayirichard@gmail.com, 2emmanuel.ajayi@fuoye.edu.ng
}

\begin{abstract}
Compression test was conducted on packaged common tomatoes in Nigeria (Roma VF) to study the effects of size and load configuration in terms of the fruits axes, deformation and stress at break and yield point of the fruits due to static loading. Different sizes of tomato were selected and ranged as big, medium sized, and small sized tomato. The bigger sizes were grouped as the A class, while the medium sizes were grouped as $B$ class, and the smaller sized as $C$ class. The samples were further classified as $A 1, A 2, B 1, B 2, C 1$ and $C 2$. While all samples having the suffix 1 were subjected to axial loading, the ones with 2 were subjected to radial loading under the Instron Universal Compression Testing Machine at the stress rate of $0.002 \mathrm{MPa}$. The study shows that majority of the samples tends to withstand higher force axially than radially for bigger and medium sized. But for the smaller tomato ranging from 35mm and below, the material was able to withstand high pressure force radially than axially before yielding.
\end{abstract}

Keywords: axial loading, radial loading, deformation, Instron universal compression test machine and tomato.

\section{INTRODUCTION}

Mechanical behavior of a compressed material at bioyield can be expressed in terms of strength parameters such as maximum sustainable load, resultant deformation and maximum sustainable stress $[1 ; 2]$. This provides a basis for predicting the occurrence of mechanical damage under an applied force. The high level of mechanical damage and diseases (often encouraged by mechanical damage) are clear indications of the need to improve the techniques of handling of perishable items like tomatoes [3]. Understanding the behaviour of the produce under static and dynamic loads provides useful information in reducing mechanical damage and enhancing quality of the fresh produce during transportation, because damage to fresh produce due to mechanical forces is among the most important causes of losses of quality [4 - 7]. A road-vehicle-load model was developed by [4] to predict the mechanical damage in loads of horticultural produce during transport. Results of the simulation of the model using predictor-corrector numerical solution techniques revealed that lightly loaded trucks caused more damage than the heavily loaded ones. It was recommended that since only selected values of some parameters were studied, investigations could be carried out on the effects of other parameters as well. These include road profiles, vehicle types and suspensions, different container types and load configurations which could provide important insights into the management of horticultural produce during transportation. However this loading may cause some level of deterioration to tomato if the load on it is beyond what the tomato can withstand. Hence if the load cannot be withstood by the strength of the material, it tends to yield gradually and later break. The aim of this study is to investigate the deterioration of tomato due to self load during transportation. The objectives of the study are to analyze the force due to static loading, which is capable of damaging tomato crop in packaging material and determine the best orientation of tomato during packaging to minimise damage.

\section{MATERIALS AND METHODS}

\subsection{Materials}

The mechanical damage due to static loading of tomato in packaging materials was determined using 
an Instron universal compression test machine. Tomato samples of different sizes of big, medium, and small were selected from Igoba farm in Akure for carrying out the experiment under the compression test machine. The response to each of the load is represented on a shear strain curve, as plotted automatically by the Instron universal compression test machine.

\subsection{Methods}

Different sizes of tomato were selected and ranged as big, medium sized, and small sized tomato. Average weights of the tomatoes were $125 \mathrm{~g}, 105 \mathrm{~g}$ and $95 \mathrm{~g}$ for big, medium and small sizes respectively while the equivalent diameters were $45 \mathrm{~mm}, 40 \mathrm{~mm}$ and $35 \mathrm{~mm}$ for the big, medium and small sizes respectively.Fruit mass was measured by using a digital balance with a sensitivity of $0.001 \mathrm{~g}$. Axial dimensions of tomato fruits as length $(L)$, width $(W)$ and thickness $(T)$ were measured by using a digital calliper gauge with a sensitivity of $0.01 \mathrm{~mm}$. The bigger sizes were grouped as the A class, while the medium sizes were grouped as $\mathrm{B}$ class, and the smaller sized as $\mathrm{C}$ class. The samples were further classified as A1, A2, B1, B2, C1 and C2. While all samples having the suffix 1 were subjected to axial loading, the ones with 2 were subjected to radial loading under the Instron Universal Compression Testing Machine at the stress rate of $0.002 \mathrm{MPa}$. The machine automatically plots the graph of the response of the material to stress at the different applied force or stress.

\section{RESULTS AND DISCUSSION}

\subsection{Results}

The results generated by the Instron universal compression test machine during the subjection of the differently selected material to loading are as shown in Figure 1 to Figure 6 and summarized in Table 1.

\subsection{Discussion}

The shape of the stress strain curve as shown in Figure 1 to Figure 3 indicates that the fruit walls may not only be elastic but may be non-linear elastic (that is, does not have a constant Young's modulus) up to the elastic limit. The Young's modulus is the tangent modulus of the initial portion of the stress strain curve or the initial gradient of the curve.

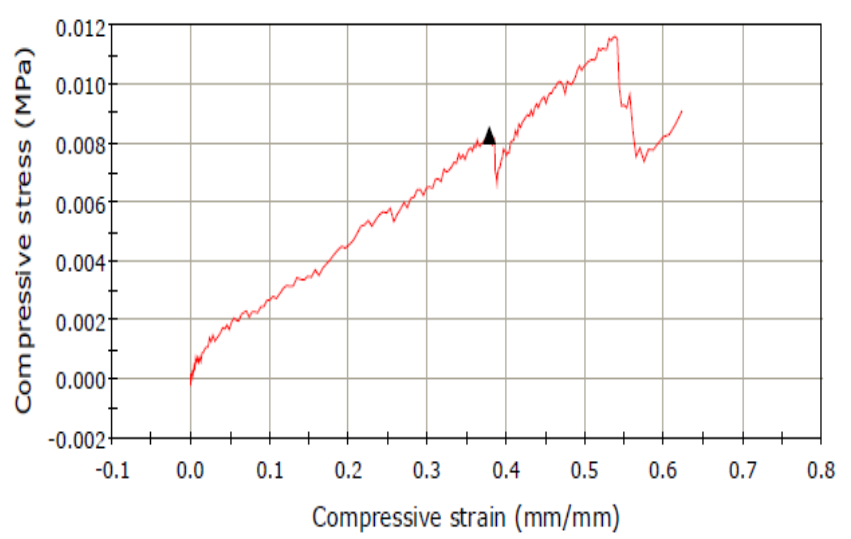

(b)

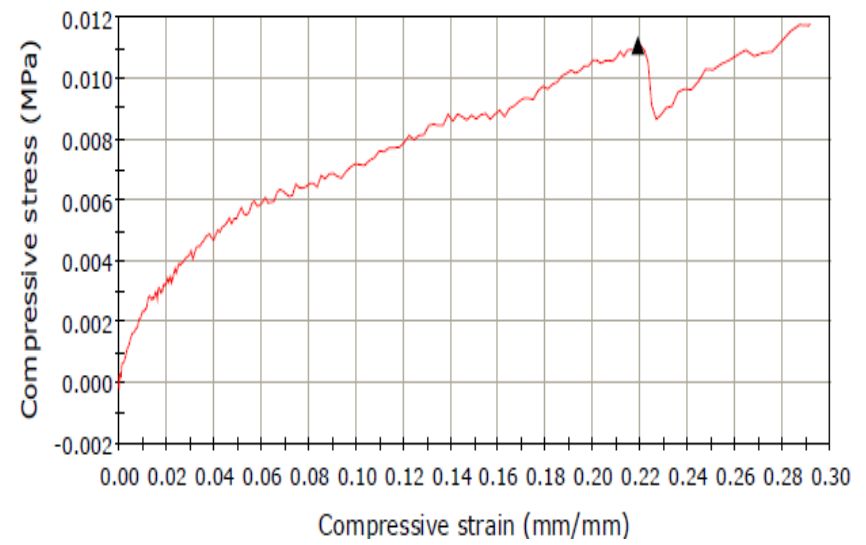

(a)

Figure 1: (a) Shear strain curve for Samples A1 subjected to axial loading, (b) Shear strain curve for Samples A2 subjected to radial loading

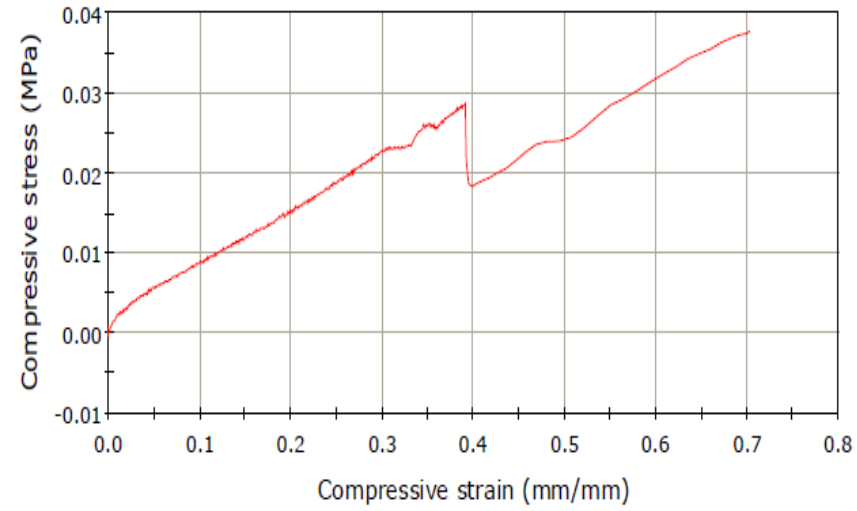

(a)

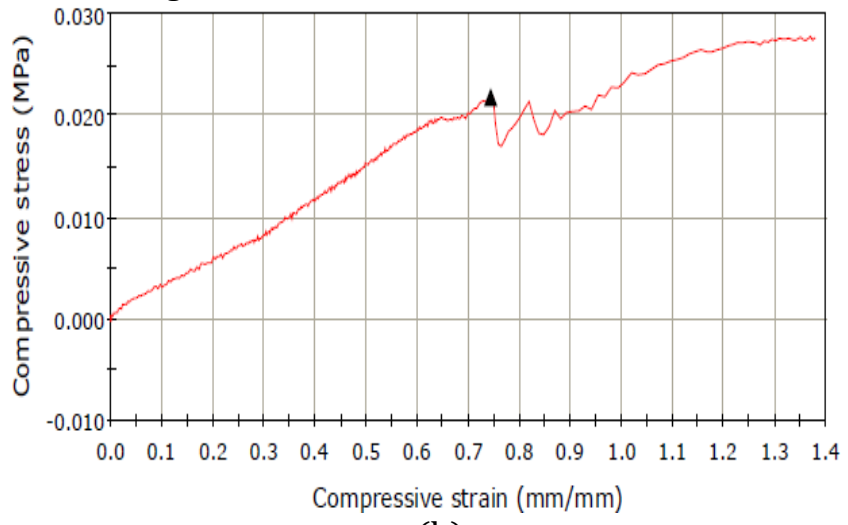

(b)

Figure 2: (a) Shear strain curve for Samples B1 subjected to axial loading, (b) Shear strain curve for Samples B2 subjected to radial loading 

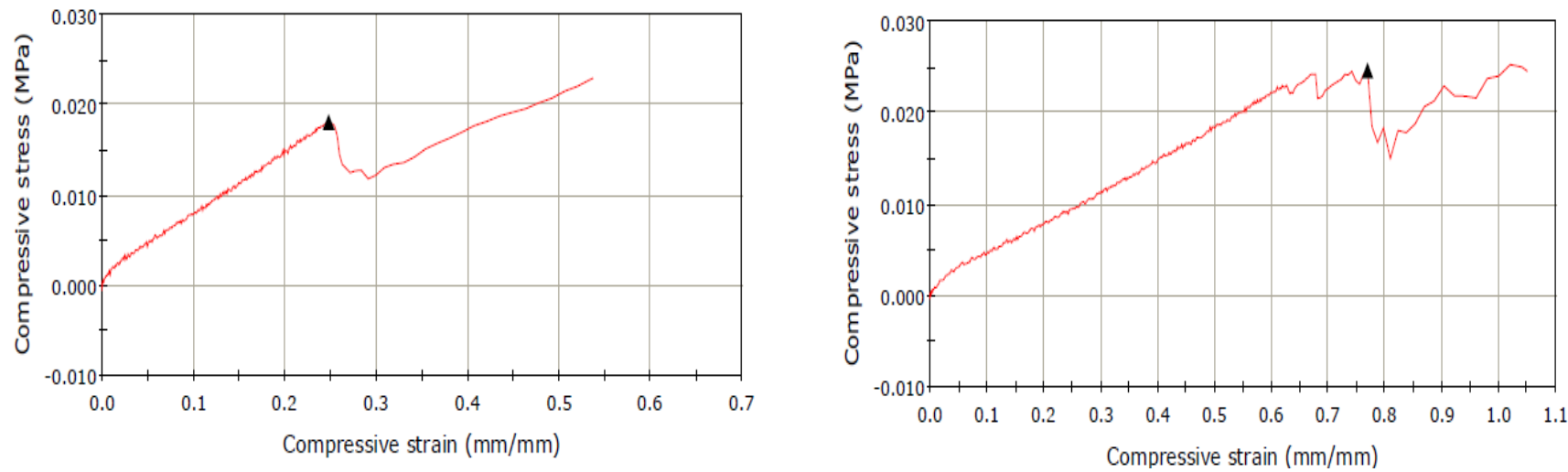

Figure 3: (a) Shear strain curve for Samples C1 subjected to axial loading, (b). Shear strain curve for Samples C2 subjected to radial loading.

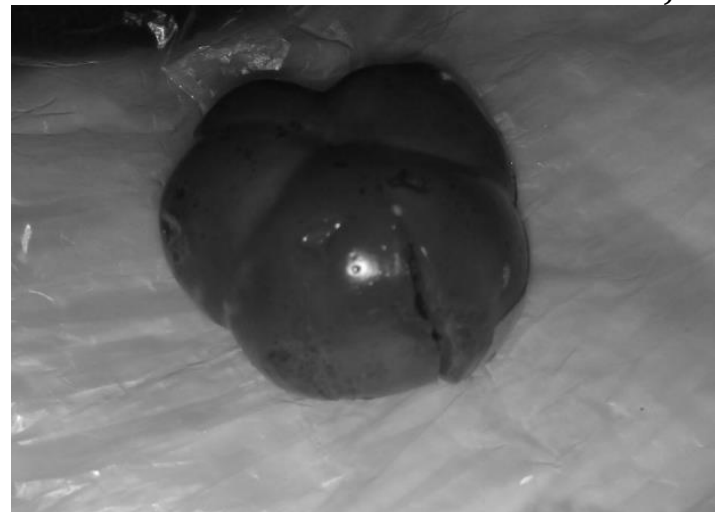

(a)

Figure 4: (a) Sample A1 after compression test,

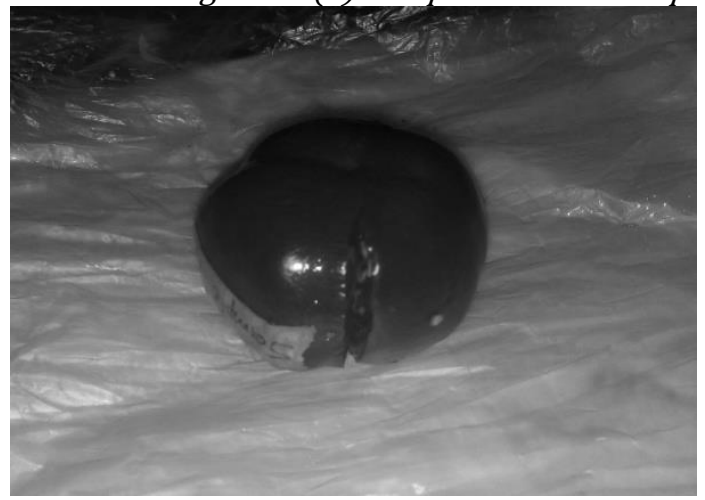

(a)

Figure 5: (a) Sample B1 after compression test, (b) Sample B2 after compression test

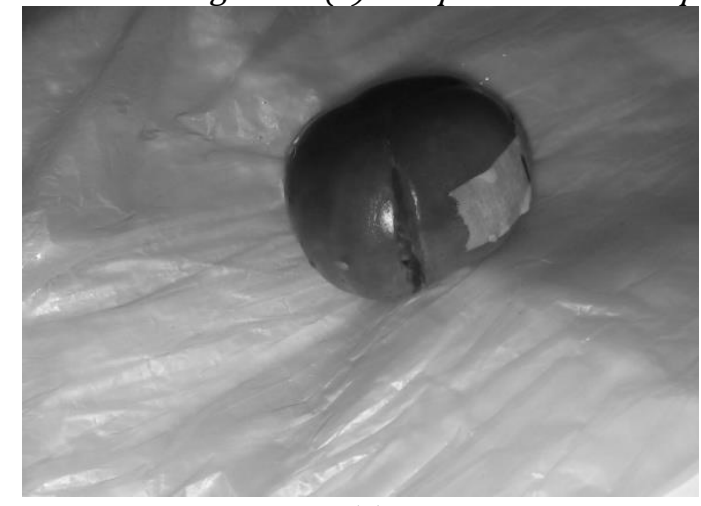

(a)

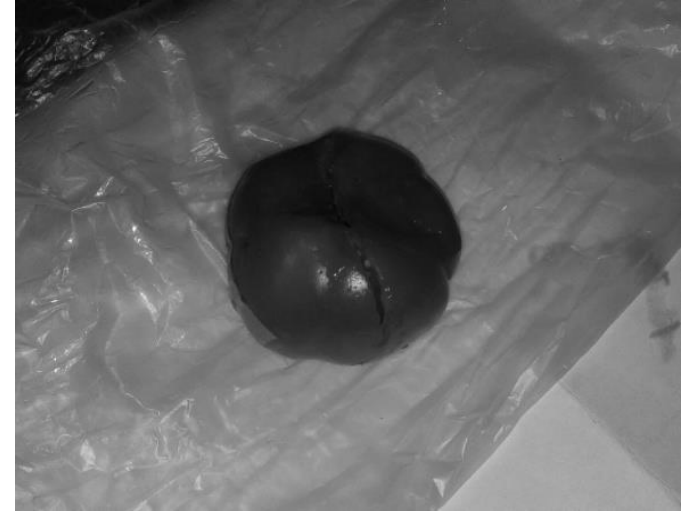

(b)

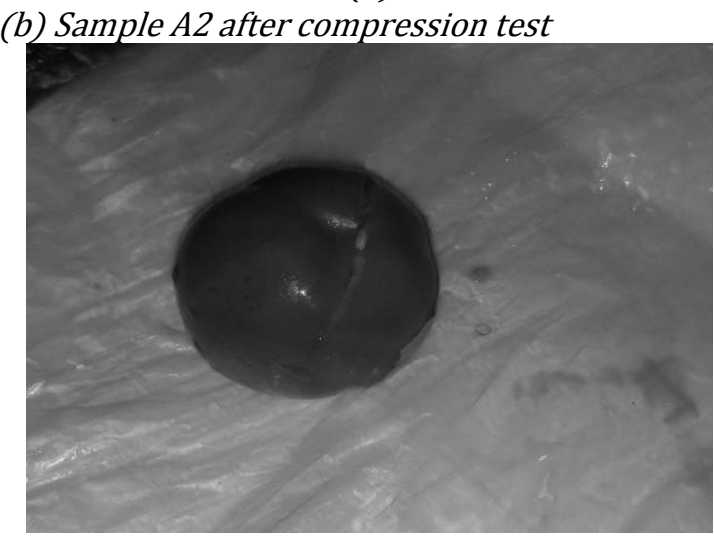

(b)

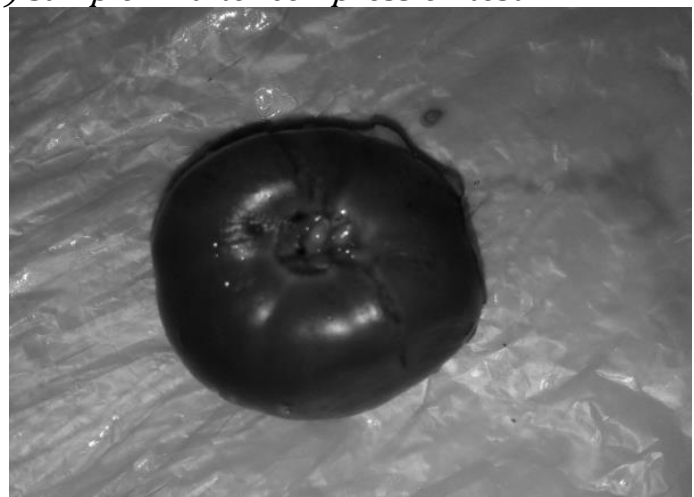

(b)

Figure 6: (a) Sample C1 after compression test, (b). Sample C2 after compression test 
Table 1: Summary of results obtained from the compression test using Instron universal compression machine.

\begin{tabular}{lcccccc}
\hline Parameters & \multicolumn{5}{c}{ Values } \\
\cline { 2 - 7 } & A1 & A2 & B1 & B2 & C1 & C2 \\
\hline Compressive strain at yield (mm/mm) & 0.22 & 0.38 & 0.39 & 0.74 & 0.25 & 0.77 \\
Compressive load at yield (N) & 17.63 & 13.20 & 38.90 & 27.40 & 22.70 & 30.90 \\
Compressive stress at yield (MPa) & 0.011 & 0.008 & 0.029 & 0.022 & 0.018 & 0.024 \\
Energy at yield (J) & 0.13 & 0.13 & 0.13 & 0.31 & 0.08 & 0.34 \\
Energy at break (J) & 0.19 & 0.31 & 0.71 & 0.88 & 0.25 & 0.52 \\
Young's Modulus (MPa) & 0.099 & 0.023 & 0.072 & 0.034 & 0.087 & 0.038 \\
Initial diameter before strain (mm) & 45.00 & 45.00 & 40.00 & 40.00 & 35.00 & 33.00 \\
\hline
\end{tabular}

The observed occurrence of sharp peaks following the elastic deformation at the end of each compression has also been attributed to soft, weak brittle materials by [8]. He particularly remarked that the point of maximum force or rupture could also occur at bioyield point. The samples subjected to radial compression exhibited increase in Young's modulus with reduction in sizes (as shown in Table 1) which may be attributed to the reduction of the interspaces' (void) volumes within the bulk, associated with compaction during loading and vibration during transportation. Knowledge of the Young's modulus of tomatoes under compression loading will help in predicting occurrence of failure under externally applied stress and enhance the design of improved packaging materials for transported tomato fruit. Young's modulus is often useful in relating the mechanical properties of the fruit to its composition and structure [9].

Medium sized tomatoes subjected to axial loading had both the highest compressive load and stress at yield while the big sized tomatoes subjected to radial loading had both the lowest compressive load and stress at yield. Meanwhile, the maximum compressive strain at yield occurred in the small sized tomatoes whereas the big sized tomatoes had the lowest compressive strain at yield. All these indicates that both size and the orientation of tomato fruit during loading and even transportation play significant roles in determining the level of deformation usually encountered during the process of transportation.

This study revealed that majority of the samples tends to withstand much force axially than radially for bigger and medium sized. But for the smaller tomato ranging from $35 \mathrm{~mm}$ and below, the material was able to withstand high pressure force radially than axially before damaging. A study titled 'Finite Design for Critical stresses of Compressed Biomaterials under Transportation' by [10] recorded $0.009 \mathrm{MPa}$ for compressive stress at yield for both axial and radial compression test on UTC tomatoes while the axial and radial compressive stresses at break were $0.015 \mathrm{MPa}$ and $0.017 \mathrm{MPa}$ respectively. This implies that the force required to yield the UTC tomato radially, is the same as the force required to damage or set it into yield axially. Meanwhile, this study shows that at a diameter of about of over $35 \mathrm{~mm}$ the force required to yield the tomato axially was more than the force required to yield the tomato radially. But for smaller sized tomato selected in this research work, slightly higher force is required to yield the material radially than axially as shown in Table 1. This may be due to the fact that the small size accounts for closely packed particles in the tomato and that it tends to withstand much force in a radial orientation than axial. This is however close to the compression test conducted by [10] on the UTC tomato in which the yielding force is the same in both axial and radial orientation. However it is advisable to load this type of tomato axially than radially when dealing with sizes that are above $35 \mathrm{~mm}$ in diameter and vice versa when the diameter is from around or close to $35 \mathrm{~mm}$ and below in order to avoid damaging of tomato, which may in turn cause deterioration of tomato during loading.

\section{CONCLUSION}

It can be seen from the study conducted on this type of tomato that it is advisable to apply load on these materials in their natural sitting position rather than applying it radially. This is because they tend to withstand much force in the axial position than radial position. It is therefore recommended that during loading and transportation of tomatoes, the material should be allowed as much as possible to sit inside the transport packaging material in its natural resting position.

\section{REFERENCES}

[1] Vursavus, K., and F. Ozguven.. Determining the effects of vibration and packaging method on mechanical damage in golden delicious apples. Turkish Journal of Agriculture and Forestry, 28 (5): 311-320. (2004). 
[2] Mencarelli, F., Salcini, M. C. \& Bellincontro, A. Consumer risk in shipping of raw fruit and vegetables. In: WimJongen (Ed) Improving the Safety of Fresh Fruits and Vegetables. Woodhead Publishing Ltd. Boca Raton FL 3348, USA. Pp 574. (2005).

[3] Idah, P. A., M. G. Yisa, O. Chukwu and 0. 0. Morenikeji. Simulated transport damage study on fresh tomato (Lycopersiconesculentum) fruits. Agric EngInt: CIGR Journal, 14 (2): Manuscript No. 2035.( 2012).

[4] Jones, C. S.; Holt, J. E.; and School, D.. A model to predict damage to horticultural produce during transport. J. Agric. Engineering Res. 50: 259-72. (1991).

[5] Roudot, A. C.; Duprat, F.; and Wenian, C.. Modeling the response of apples to loads. J. Agric. Engin. Res. 48: 249-59. (1991).

[6] Jan, J. L, X. Vandewalle, and J. De Baedemaeker.. Influence of global shape and internal structure of tomatoes on the resonant frequency. J. of Agricultural Engineering Research, 66: 41-49. (1997).

[7] Batu, A.. Some Factors Affecting on Determination and Measurement of Tomato Firmness. Tropical Journal of Agriculture and Forestry, 22: 411-418. (1998).

[8] Fellows P. J.. Food Processing Technology, Principles and Practice. Wood-head Publishing Company Limited, Great Abington Cambridge, pp. 99. (2009).

[9] Babarinsa, F. A and Ige, M. T..Young's Modulus for Packaged Roma Tomatoes under Compressive Loading. International Journal of Scientific \& Engineering Research. 3(10):1 - 7. (2012).

[10] Ihueze, C. C., Okafor, C. E., Ogbogbe, P. O. Finite design for critical Stresses of Compressed Biomaterials under Transportation. Proceedings of the World Congress on Engineering Vol. III. WCE 2013, July 3-5, 2013, London. (2013). 